\title{
Analytical Study of Intrauterine Fetal Death and Associated Maternal Conditions at a Tertiary Centre
}

Nasreen Noor ${ }^{1}$, Shazia Parveen ${ }^{1}$, Iti Madan ${ }^{1}$, Aarzoo Hoda ${ }^{1}$ ${ }^{1}$ Department of Obstetrics and Gynaecology, JNMCH, AMU, Aligarh, U.P, India

\author{
Article History \\ Received: 24.08 .2020 \\ Accepted: 09.09.2020 \\ Published: 30.09 .2020 \\ Journal homepage:
}

https://www.easpublisher.com/easjms

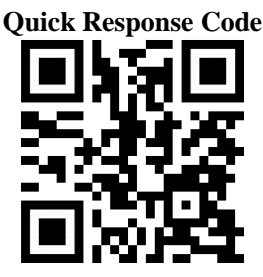

Abstract: Introduction: Stillbirth remains an enormous challenge in the care of pregnant women, especially in developing countries. Intrauterine fetal death (IUFD) is an important indicator of maternal and perinatal health of a given population. The objective of the study was to evaluate the socio-epidemiological and etiological factors of IUFD. Materials and Methods: The present study was a prospective observational analytical study which was conducted in Department of Obstetrics and Gynaecology, JNMCH, Aligarh from January 2019 to July 2019 and includes 160 pregnant women with confirmed intrauterine fetal death (IUFD) on USG. Informed consent was taken from all the participants. A predesigned proforma was used to collect relevant information from all those who gave consent to participate in the study. The details of complaints at admission, obstetrical history, menstrual history, examination findings, per vaginal examination findings, mode and method of delivery, and fetal outcome were recorded. Results: Through this study, overall 3900 deliveries was recorded, out of them 160 women were of stillbirth. The incidence of IUFD was 41/1000 live births. The maximum age group of mothers were at rang 20-25years. Majority cases of intrauterine fetal death were diagnosed among 32-36 weeks of gestational age. There were $112(70 \%)$ women who were unbooked with no antenatal visits and rest 48 $(30 \%)$ were booked women. Majority of stillbirth $137(62 \%)$ weighted less than $2500 \mathrm{mg}$. Amongst the identifiable causes, severe preeclampsia was present in $32(20 \%)$ of the women. This was found to be the most common cause responsible for IUFD followed by anaemia which was present in $26(16 \%)$ of women, fever in $10(6.2 \%)$, gestational diabetes mellitus in $7(5.3 \%)$, UTI in $5(4.1 \%)$, deranged coagulation in $7(3.4 \%)$ and deranged RFT in $1(0.6 \%)$ of women. Conclusions: The present study is an effort to compile a profile of maternal, fetal and placental causes culminating in IUFD at our center. This emphasizes the importance of proper antenatal care and identification of risk factors and its treatment. Institutional deliveries should be promoted to prevent IUFD. Majority of fetal wastage can be prevented with universal and improved antenatal care.

Keywords: Intrauterine fetal death (IUFD), Anaemia, Congenital malformations, Hypertensive disorders.

Copyright @ 2020: This is an open-access article distributed under the terms of the Creative Commons Attribution license which permits unrestricted use, distribution, and reproduction in any medium for non-commercial use (Noncommercial, or CC-BY-NC) provided the original author and source are credited.

\section{INTRODUCTION}

Stillbirth remains an enormous challenge in the care of pregnant women, especially in developing countries like India (Dash, M. M., \& Behera R. B. 2017). The occurrence of IUFD or stillbirths can constitute a nightmare for parents and the attending obstetricians and paediatricians. It is considerably all the more anguishing, with a sentiment of thrashing to the clinician, on the off chance that it happens suddenly and the reason can't be clarified. Intrauterine fetal death is an important indicator of maternal and perinatal health of a given population. Intrauterine death (IUD) definition incorporates antepartum death past 20 weeks of development or birth weight $\geq 500 \mathrm{~g}$ when gestational age not known (WHO) (Stanton, C. et al., 2006). As indicated by the 2003 amendment of the procedures for Coding cause of Fetal Death under ICD-10, the
National Centre for Health Statistics characterizes IUFD as death before the total removal or extraction from its mother of product of conception, regardless of pregnancy duration and which isn't a prompted end of pregnancy (Gehlot, H. et al., 2017). In UK, stillbirths are those babies born dead after 24 weeks of gestation. The definition recommended by WHO for international comparison is a baby born with no signs of life at or after 28 weeks' gestation (Patel, S. et al., 2014). In other countries, such as Australia, Canada, Finland, New Zealand, Iceland and many states in the USA, fetal death occurring after 20 weeks of gestation is termed as stillbirth (Joseph, K.S. et al., 2015).

In the developing countries the bulk of intrauterine deaths are intrapartum and are attributed commonly to avoidable factors (Swailem, A.R. et al., 1988; \& El Gilany, A.H. 2000). In contrast, stillbirths in 
developed countries are largely antepartum with no apparent cause (Cole, S.K. 1989; \& Grant, A. et al., 1989). Most intrapartum stillbirths are associated with obstetric emergencies, whereas antepartum stillbirths are associated with maternal diseases, and infections (Lawn, J.E. et al., 2011). They include pre-eclampsia, intrauterine growth restriction, abruptio placentae, infections, umbilical cord complications, and environmental hazards. Maternal smoking, advanced maternal age, high parity, obesity, and obstructed labor are also widely recognized risk factors for stillbirth (Guevvera, Y. 2006; \& Lawn, J. et al., 2015). Another report detailed that absence of pre-birth care, blocked off or constrained medical services is the main consideration answerable for high peri-natal demises in developing nations as Asia and sub Saharan Africa (AlKadri, H.M., \& Tamim, H.M. 2012).

The estimated global still birth rate worldwide was 18.4 per 1000 total birth in 2015 (Blencowe, H. et al., 2015) with more than 3 million early neonatal deaths occur every year. A vast majority $(98 \%)$ takes place in developing countries where stillbirths represent over half of the perinatal deaths (Guevvera, Y. 2006). Underreporting in developing countries like India is normal, which makes correlations much progressively troublesome (Faiza. A., \& Muhammad, T. 2019). Complications during pregnancy and childbirth are known to be closely associated with high stillbirth and perinatal mortality rate (Kusiako, T. et al., 2000).

The main objective of our investigation is to inspect the maternal conditions related with intrauterine fetal demise with explicit reference to clinical characterstics, maternal risk factors and to scrutinize the preventable factors for fetal demise. As an outcome, our study makes it conceivable to know the degree of the perinatal death issue and in addition fills in as a basis for future research studies on intrauterine fetal demise and give a few suggestions or recommendations for researcher and health care workers.

\section{Material AND Methods}

The present study was a prospective observational analytical study which was conducted in Department of Obstetrics and Gynaecology , JNMCH , Aligarh from January 2019 to July 2019 and includes 160 pregnant women with confirmed intrauterine fetal death (IUFD) on USG. This study aimed to evaluate and understand the prevalence, epidemiological and etiological factors, Clinical profile of IUFDs. After approval by Institutional ethic committee and informed written consent. All women were thoroughly interrogated and systematically examined and optimally investigated and all the findings were recorded on a predesigned proforma. The patients mainly presented with chief complaints of decreased or loss of fetal movements, history of leaking, bleeding per vagina. Socio-demographic characters and clinical parameters were noted including maternal age, parity, gestational age, mode of delivery, birth weight, obstetric complication, maternal, and placental risk factors were recorded. The obstetrical history included parity, abortions, stillbirth, neonatal death, lower segment caesarean section (LSCS), preterm delivery, antepartum haemorrhage (APH) or any other medical disorder in previous pregnancy. History regarding her menstrual cycles, past history, personal history was also elicited and noted in the proforma. General examination, local examination findings, per speculum and per vaginal examination was done thoroughly and systematically and relevant investigations were also done. All the women with gestational period beyond 20 weeks to full term pregnancy having normal/malformed foetus were included in the study while babies born below 20weeks of gestation, fetus weighing below $500 \mathrm{~g}$ were excluded from the study.

\section{RESULTS}

The present study consisted of 160 women of IUFD which occurred during the study period of 6 months. A total of 3900 deliveries occurred in our institute during the study period. The incidence of IUFD was 41 per 1000 live birth.

Table I: Sociodemographic parameters

\begin{tabular}{lll}
\hline Parameters & No. of Women & Percentage \\
\hline Maternal age (years) & & \\
$<20$ & 32 & 20.0 \\
$20-25$ & 84 & 52.5 \\
$26-30$ & 26 & 16.25 \\
$31-35$ & 08 & 5.00 \\
$35-40$ & 06 & 3.75 \\
$>40$ & 04 & 2.50 \\
Parity & & \\
G1 & 61 & 38.12 \\
G2 & 51 & 31.88 \\
G3 & 30 & 18.75 \\
G4 & 12 & 7.50 \\
G5 & 6 & 3.75 \\
& & \\
Gestational & & \\
age(weeks) & 21 & 13.12 \\
20-28 weeks & 38 & 23.75 \\
28-32 weeks & 52 & 32.50 \\
32-36 weeks & 17 & 10.62 \\
36-40 weeks & 27 & 16.88 \\
$>$ 40 weeks & & \\
Area & 122 & 76 \\
Rural & 38 & 24 \\
Urban & & \\
Booking status & 48 & \\
Booked & 112 & \\
Unbooked & & \\
\hline
\end{tabular}

Table I shows that majority of the fetal deaths $(52.5 \%)$ occurred in women between age range of 20 25 years and minority of the fetal deaths (2.5\%) occurred in women above 40 years of age and maximum number $61(38.12 \%)$ of women were 
primigravida. The majority of IUFD fetuses were diagnosed among 32-36, 28- 32 and $>40$ weeks in range $32 \%, 23 \%$ and $16 \%$ respectively. Out of total IUFD women, $76 \%$ of the women were from the rural areas while $24 \%$ belongs to urban areas. There were 112 (70\%) women who were unbooked with no antenatal visits and rest 48 (30\%) were booked women.

Table II: Distribution according to gender and birth

\begin{tabular}{lcc}
\multicolumn{3}{c}{ weight } \\
\hline Gender & $\begin{array}{c}\text { No. of } \\
\text { Women }\end{array}$ & $\begin{array}{c}\text { Percentage } \\
\text { Male }\end{array}$ \\
Female & 93 & 58 \\
& 67 & 42 \\
\hline Birth weight & & \\
(kgs) & 111 & 69 \\
$<2.5$ & 49 & 31 \\
$\geq 2.5$ & & \\
\hline
\end{tabular}

Table IV shows that majority of the women delivered male fetuses $93(58 \%)$ and $67(42 \%)$ were female fetuses. Majority of stillbirth 137 (62\%) weighted less than $2500 \mathrm{mg}$.

Table III: Maternal risk factor associated with IUFD

\begin{tabular}{lcc}
\hline Maternal risk factor & $\begin{array}{c}\text { No. of } \\
\text { Women }\end{array}$ & Percentage \\
\hline Severe preeclampsia & 32 & 20 \\
Anemia & 26 & 16 \\
Non severe & 08 & 05 \\
preeclampsia & & \\
Chronic hypertension & 04 & 2.5 \\
Eclampsia & 03 & 02 \\
Jaundice & 08 & 05 \\
Fever & 10 & 6.2 \\
Unknown & 10 & 6.2 \\
Diabetes & 07 & 5.3 \\
UTI & 05 & 4.1 \\
Deranged coagulation & 07 & 3.4 \\
Deranged RFT & 01 & 0.6 \\
\hline
\end{tabular}

According to Table III, amongst all maternal factors responsible for IUFD, severe preeclampsia was present in 32 (20\%) of the women. This was found to be the most common cause responsible for IUFD followed by anaemia which was present in $26(16 \%)$ cases, feverin10(6.2\%), gestational diabetes mellitus in $7(5.3 \%)$, UTI in $5(4.1 \%)$, deranged coagulation in $7(3.4 \%)$ and deranged RFT in $1(0.6 \%)$ of women.

Table IV: Fetal risk factor associated with IUFD

\begin{tabular}{lcc}
\hline Fetal risk factor & $\begin{array}{c}\text { No. of } \\
\text { Women }\end{array}$ & Percentage \\
\hline Congenital anomaly & 10 & 6.2 \\
Previous history of & 05 & 3.1 \\
IUFD & & \\
IUGR & 05 & 3.1 \\
Rupture uterus & 02 & 1.2 \\
Rh isoimmunization & 03 & 1.8 \\
\hline
\end{tabular}

Among all fetal risk factors, congenital anomaly was present in $10(6.2 \%)$ of women, being the most common cause followed by IUGR and previous history of IUFD in (5) $3.1 \%$ of women, $\mathrm{Rh}$ isoimmunisation was present in $3(1.8 \%)$ of women (Table IV).

Table V: Placental risk factor associated with IUFD

\begin{tabular}{lcc}
\hline Placental risk factor & $\begin{array}{c}\text { No. of } \\
\text { Women }\end{array}$ & Percentage \\
\hline Accidental & 08 & 05 \\
haemorrhage & & \\
Placenta Previa & 01 & 1.2 \\
PROM & 05 & 2.5 \\
\hline
\end{tabular}

Amongst the placental risk factors, accidental hemorrhage was found to be the most common cause $8(5 \%)$ responsible for IUFD followed by PROM 5(2.5) and placenta previa.01 (1.2).

Table VI: Distribution of women according to mode of delivery

\begin{tabular}{lccc}
\hline Method of delivery & No. of Women & Percentage \\
\hline Vaginal & 151 & 94 & \\
Spontaneous & 97 & \multicolumn{2}{c}{60} \\
Induction & 54 & \multicolumn{2}{c}{34} \\
Operative & 09 & 06 & 56 \\
Laparotomy & 05 & 22 & \\
Caesarean section & 02 & 22 & \\
Hysterotomy & 02 & & \\
\hline
\end{tabular}

Table VI shows that $94 \%$ women delivered vaginally and operative delivery occurred in $6 \%$ of women. Out of 160 IUFDs $60 \%$ had spontaneous onset of labor while $34 \%$ needed induction of labor, 5 women underwent laparotomy for repair of rupture uterus , 2 had LSCS and hysterotomy .

\section{Discussion}

The concrete calculation of the incidence of IUFD is not promising due to under coverage of all cases (Stanton, C. et al., 2006) ${ }^{\circ}$ The incidence of IUFD calculated in our study is $41 / 1000$ live births. In western countries reported incidence of IUFD ranges from $4.7 \%$ to $12.0 \%$, whereas the incidence rate reported from different centers in India is between 24.4- $41.9 \%$ (Mathuriya, G. B.N. 2015; Sharma, S. et al., 2016; \& Dasgupta, S., \& Saha, I. M.A. 1997), which is in harmony to present study. One of the reasons for obtaining this excessive occurrence of fetal demise in our study is that our institute is the sole leading tertiary center catering the West Uttar Pradesh, as a result the majority of the complicated and high- risk cases are referred to our center. Many factors like illiteracy, low socioeconomic category and underprovided monitoring facilities in rural areas are responsible for high figure of unsupervised pregnancy which could be the other reason for high incidence of IUFD. 
Most of studies have demonstrated that intrauterine demise was firmly identified with low or even nil intake of folic acid and or iron supplementation during pregnancy are the risk factors for neural tube defects in the fetus and severe anemia in mothers, resulting in fetal anomaly resulting into fetal death and related complications in different mothers. Adequate and expected prenatal care is related with better pregnancy results (Patel, S. et al., 2014)

Nutritional deficiency and anaemia are leading cause of poor pregnancy outcome. Majority of our patients were anaemic. The increased risk of fetal death is present amongst the age group of 20-25 yrs. This is on the grounds that the greater part of the married women in India completes their family before 35 years old. Another study reported no considerable rise in the number of IUFD with maternal age (Flenady, V. et al., 2011).

Increased risk of IUFDs is seen amongst primigravidas (Dasgupta, S., \& Saha, I. M.A. 1997), dissimilar to our experience in other study conducted rate of IUFD was found to be higher in multigravida (Korde-NayakVaishali, N., \& Gaikwad Pradeep, R. 2008). Prematurity is an additional risk issue that contributes among the many risk factors for IUFD. Another study stated that the maximum number of intrauterine fetal demise were because of prematurity (47.5\%) which were between 26-30 and 31-35 weeks of gestation and comparable observations were reported in one more literature that $57.8 \%$ of IUFD were of prematurity (Kumari, C. et al., 2001). In present study majority of IUFD cases were unbooked patient $(70 \%)$ which consistent with another study result which indicated that unbooked cases accounted for $80.9 \%{ }^{[1]}$. Furthermore in our study, Majority of stillbirth $111(69 \%)$ weighted less than $2500 \mathrm{mg}$.

The most common maternal factor found to be responsible for IUFD is severe preeclampsia and its complications which is comparable with the other study accounted $17 \%$ and $19 \%$ respectively (Stillbirth Collaborative Research Network Writing Group. (2011; \& Ravikumar, M., \& Devi A. B.V. 1996), followed by anaemia. This high incidence of severe anemia may be due to poor compliance with oral folic acid or oral iron therapy. This is consistent with another study that reveals that anemia associated with stillbirth and represents $11.2 \%$. The results of another study, anaemia was seen in $16 \%$ of cases of stillbirth which was consistent with our observation but it could be prevented by appropriate antenatal concern and supplementation with folic acid and iron are recommended (Choudhary, A. et al., 2014).

Among all fetal risk factors, incidence of congenital malformations was $6.2 \%$ which was lower to that reported from other studies, being most common cause followed by IUGR and previous history of IUFD.
Amongst the placental risk factors, accidental hemorrhage was found to be the most common cause responsible for IUFD followed by PROM and placenta praevia which is similar with another study that found abruption placenta in $12 \%$ of IUFD . In current study, maximum number of women delivered vaginally and $60 \%$ had spontaneous onset of labor while $34 \%$ underwent induction of labor. Similar results were seen in another study which reported that the normal vaginal delivery occurred in $89.4 \%$. Our study show that is appropriate intervention in tertiary health care center can definitely reduce rate the IUFD.

\section{CONCLUSION}

The present study is an effort to compile a profile of maternal, fetal and placental causes culminating in IUFD at our center. This emphasizes the importance of proper antenatal care and identification of risk factors and its treatment. Furthermore inadequate or nil intake folic acid and iron therapy are at risk of neural tube defects in the fetus and severe anemia in mother, resulting in fetal death and complications. Institutional deliveries should be promoted to prevent IUFD. Majority of fetal wastage can be prevented with universal and improved antenatal care.

\section{REFERENCES}

1. Al-Kadri, H.M., \& Tamim, H.M. (2012). Factors contributing to intra-uterine fetal death. Archives of gynecology and obstetrics, 286(5), pp.1109-1116.

2. Blencowe, H., Cousens, S., Jassir, F.B., Say, L., Chou, D., Mathers, C., Hogan, D., Shiekh, S., Qureshi, Z.U., You, D., \& Lawn, J.E. (2015). Lancet Stillbirth Epidemiology Investigator Group. National, regional, and worldwide estimates of stillbirth rates in2015, with trends from 2000: a systematic analysis. Lancet Glob Health 2016;4:e98-108.

3. Choudhary, A., Gupta, V. (2014). Epidemiology of intrauterine fetal deaths: a study in tertiary referral centre in Uttarakhand. IOSR Journal of Dental and Medical Sciences, 13(3), pp.03-06.

4. Cole, S.K. (1989). Scottish stillbirth and neonatal death report 1988. Information and Statistics Division, Common Services Agency for the Scottish Health Services. Edinburgh, pp. 950-974.

5. Dasgupta, S., \& Saha, I. M.A. (1997). A study on profile of stillbirths. J Indian Med Assoc. 95, 1758.

6. Dash, M. M., \& Behera R. B. (2017). Etiology and management of intrauterine fetal death. MedPulse International Journal of Gynaecology, 3(2), pp 5963.

7. El Gilany, A.H. (2000). Perinatal mortality in the northern region of Saudi Arabia. Middle East Paediatrics, 5(2), pp38-44

8. Faiza. A., \& Muhammad Taher. (2019). "Analytical Study of Intrauterine Fetal Death Cases and Associated Maternal Conditions in Northeast 
of Libya." .IOSR Journal of Nursing and Health Science (IOSR-JNHS), 8 (03), 2019, pp. 67-71.

9. Flenady, V., Koopmans, L., Middleton, P., Frøen, J.F., Smith, G.C., Gibbons, K., Coory, M., Gordon, A., Ellwood, D., McIntyre, H.D., \& Fretts, R. (2011). Major risk factors for stillbirth in highincome countries: a systematic review and metaanalysis. The lancet, 377(9774), pp.1331-1340.

10. Gehlot, H., Nagar, G.G., Sharma, S., \& Yadav, O.P. (2017). A prospective analytical study of intrauterine fetal death cases and associated maternal condition at a tertiary centre. Int J Reprod Contracept Obstet Gynecol 2017;6:3392-6.

11. Grant, A., Valentin, L., Elbourne, D., \& Alexander, S. (1989). Routine formal fetal movement counting and risk of antepartum late death in normally formed singletons. The Lancet, 334(8659), pp.345-349.

12. Guevvera, Y. (2006). World Health Organisation: Neonatal and perinatal mortality: country, regional and global estimates, sun, cebu.

13. Joseph, K.S., Kinniburgh, B., Hutcheon, J.A., Mehrabadi, A., Dahlgren, L., Basso, M., Davies, C., \& Lee, L. (2015). Rationalizing definitions and procedures for optimizing clinical care and public health in fetal death and stillbirth. Obstetrics \& Gynecology, 125(4), pp.784-788.

14. Korde-NayakVaishali, N., \& GaikwadPradeep, R. (2008). Causes of stillbirth. The Journal of Obstetrics and Gynecology of India, 58(4), pp.3148.

15. Kumari, C., Kadam, N.N., Kshirsagar, A., \& Shinde, A. (2001). Intrauterine fetal death: A prospective study. The Journal of Obstetrics and Gynecology of India, 51(5), pp.94-97.

16. Kusiako, T., Ronsmans, C., \& Van der Paal, L. (2000). Perinatal mortality attributable to complications of childbirth in Matlab, Bangladesh.
Bulletin of the World Health Organization, 78, pp.621-627

17. Lawn, J., Shibuya, K., \& Stein, C. (2005). No cry at birth: global estimates of intrapartum stillbirths and intrapartum-related neonatal deaths. Bulletin of the World Health Organization, 83, pp.409-417

18. Lawn, J.E., Blencowe, H., Pattinson, R., Cousens, S., Kumar, R., Ibiebele, I., Gardosi, J., Day, L.T., Stanton, C. (2011). Lancet's Stillbirths Series Steering Committee. Stillbirths: Where? When? Why? How to make the data count? The Lancet, 377(9775), pp.1448- 1463.

19. Mathuriya, G. B.N. (2015). Evaluation of intrauterine foetal death at tertiary care centre. Inter J Medical Sci Res Prac. 2(3), 139-142.

20. Patel, S., Thaker, R., Shah, P., \& Majumder, S. (2014). Study of causes and complications of intra uterine fetal death (IUFD). International Journal of Reproduction, Contraception, Obstetrics and Gynecology, 3(4), pp.931-935.

21. Ravikumar, M., \& Devi, A.B.V. (1996). Analysis of stillbirths in referral hospital. The Journal of Obstetrics and Gynecology of India, 46, pp.791796.

22. Sharma, S., Sidhu, H., \& Kaur, S. (2016). Analytical study of intrauterine fetal death cases and associated maternal conditions. 6(1), 11-13.

23. Stanton, C., Lawn, J. E., Rahman, H., WilczynskaKetende, K., \& Hill, K. (2006). Still birth rates: Delivering estimates in 190 countries. Lancet 367, 1487- 1494

24. Stillbirth Collaborative Research Network Writing Group. (2011). Causes of death among stillbirths. JAMA network, 306(22), pp.2459-2468.

25. Swailem, A.R., Serenius, F., Edressee, A.W., \& Ohlsson, A. (1988). Perinatal mortality in a Saudi maternity hospital. Acta Padiatrica, 77, pp.57-69. 